\title{
ニューラルネットワークによる抄紙機の断紙要因解析*
}

\author{
日本製紙株式会社 中央研究所 $\bigcirc$ 宮 西 孝 則 \\ 日本製紙株式会社 岩国工場嶌田浩 孝
}

\section{Using Neural Networks to Diagnose Web Breaks on \\ a Newsprint Paper Machine}

\section{Takanori Miyanishi}

Central Research Laboratory,

Nippon Paper Industries, Co., Ltd.

Hirotaka Shimada

Iwakuni Mill,

Nippon Paper Industries, Co., Ltd.

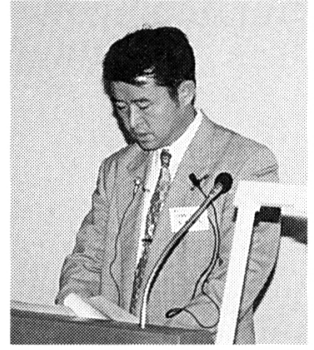

宮西孝則

Artficial neural networks hold great promise for solving problems that have been extremely difficult to solve using conventional methods. We used an artificial neural network to diagnose paper web breaks on a commercial newsprint paper machine. Process data for pulping and papermaking operations were collected from paper machine's distributed control sysytem. Additional data were obtained from on-line wet end sensors (zeta potential, first pass retention, conductivity and $\mathrm{pH}$ ) that were installed for this study. The essential variables contributing to paper web breaks were extracted using a three-stage multilayer neural network and back-propagation method. Great savings of production costs were achieved: the number of web breaks was reduced, fiber loss in the effluent was decreased, and operators spent less time cleaning, rethreading, and restarting the paper machine.

\section{1.はじめに}

紙パルプ産業は装置産業であり，品質安定や生産性 向上のためにはプロセスの最適操業は大きな課題であ る。諸外国では大学や紙パ企業を中心に, プロセスデ ータをルーチン的に収集しているコンピュータデータ ベースを利用して, プロセスの解析, 診断やモデリン グなどに関する研究をさかんに行っている。このよう な研究には大別して 2 つのアプローチがあり, 各々長 所短所を持っている。その一つはプロセスモデル機構 によるモデルベース的方法であり，もう一つは経験的 知識に基づくルールベース的方法である。後者におい

\footnotetext{
*第 4 回製紙技術セミナ一講演
}

て，人間の脳を真似て自分で学習を行い，パターン認 識能力に優れているというユニークな特徵を持つニュ ーラルネットワーク $(\mathrm{NN})$ の利用が最近さかんである。 これはしばしば古典的な統計解析法と比較して研究さ れる。紙パルプ工程は非常に複雑で, 正確なプロセス モデルの構築は非常に困難である。その点ルールベー ス法は知識獲得が容易であり実践的である。なかでも ニューラルネットワークは一種の非線形回帰法とみな すことができ, 従来の線形多変量解析法よりも高い判 別能力が得られる可能性がある。そこで本研究では, ニューラルネットワークと代表的な多変量統計法であ る主成分分析によって新聞抄紙機の断紙要因解析を行 い，有用な知見を得たので報告する。 


\section{2. データの収集}

解析に用いたデータは, 新聞抄紙機の約 4 週間のプ ロセスと紙品質のデータで全部で 41 項目収集した (表 1)。時系列方向には 1 直の平均值を求め（約 8 時 間の平均), データセットは説明変数が 41 コ, 79 コ のオブザベーション (26 日間 +1 直) から構成されて いる。尚，断紙直後 1 時間のデータの変化は断紙の結 果であって断紙要因ではないので平均値の計算には使 用しなかった。デー夕収集期間中に断紙が発生した直 は計 9 回あった。解析に先立ちデー夕は平均と分散を 標準化した。これは単位が異なるために大きな分散值 をもつ変数が，見掛け上大きな寄与を示すのを防ぐた めである。

\section{3. ニューラルネットワーク}

現実の問題には，『あいまいさ』とか『矛盾』など がつきもので，人間はこのような問題を非常に巧みに 処理する。この能力を従来のノイマン型コンピュータ で実現することは，本質的に困難である。そこで人間 の神経細胞（ニューロン）のモデルを用いた人工のシ ステムが考え出され，これらを総称してニューラルネ ットワーク (NN) という。 NNの一番の特徴は, 学 習能力があることである。従来のコンピュータでは学
習というのはプログラミングに相当する。一方ニュー ロは学習デー夕を与えることによって，それに合うよ うに自分自身の構造を変化させていく（自己組織化） ので，これは大変なメリットである。NN には様々な 種類があるが，エンジニアリングプロセスのモデリン グに最も適しているのは，バックプロパゲーション (BP) モデルである（図 1)。BP モデルは，ニューロ ンが階層状に結合した構造をもつモデルである（入力 層, 中間層, 出力層)。各階層の二ューロンは, その 前後の層のすべてのニューロンと結合し，それぞれ異 なる結合の強さ（荷重）をもっている。ある層（中間 層または出力層）の $\mathrm{j}$ 番目のニューロンの出力值 $\mathrm{Oj}$ は次のように計算される。

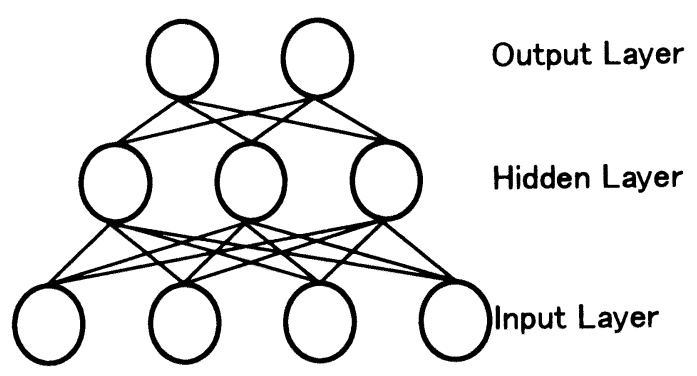

Fig.1 Typical neural network architecture

Table 1 Variables used in web break diagnosis

Bel-Baie 2,280 inches, $400 \mathrm{t} /$ day, $1,000 \mathrm{~m} / \mathrm{min}$

\begin{tabular}{r|l|c|l|c|l}
\hline No. & \multicolumn{1}{|c|}{ Variable } & No. & \multicolumn{1}{c|}{ Variable } & No. & \multicolumn{1}{c}{ Variable } \\
\hline 1 & SBKP freeness & 15 & Couch vacuum & 29 & Alum \\
2 & GP freeness & 16 & Dryer steam pressure & 30 & Retention aid \\
3 & TMP freeness & 17 & Wet web moisture & 31 & SBKP ratio \\
4 & 1 DIP freeness & 18 & Basis weight & 32 & GP ratio \\
5 & 2 DIP freeness & 19 & Paper moisture & 33 & TMP ratio \\
6 & Inlet pH & 20 & Caliper & 34 & 1 DIP ratio \\
7 & Inlet temperature & 21 & Spot (large) & 35 & 2 DIP ratio \\
8 & Inlet condutivity & 22 & Spot (small) & 36 & Tear strengh \\
9 & Inlet zeta potential & 23 & Black spot (large) & 37 & Tensil strength \\
10 & Inlet consistency & 24 & Black spot (medium) & 38 & Stretch \\
11 & White water consistency & 25 & 2 P/3 P draw & 39 & Brightness \\
12 & Inlet pressure & 26 & 3 P/1 D draw & 40 & Opacity \\
13 & Wire suction box vacuum & 27 & Machine speed & 41 & Stuff box freeness \\
14 & Pick up felt vacuum & 28 & Broke ratio & & \\
\hline
\end{tabular}

1-35 were monitored by on-online instruments every 3 minutes.

36-41 were manually measured in a mill laboratory every 4 hours.

8 hour averages were calculated and used for break analysis. 
$\mathrm{Oj}=\mathrm{f}($ netj)

ここで,

荷重和 $n e t j=\Sigma(\mathrm{Wji} \cdot \mathrm{Oj})+\theta \mathrm{j}$

$\mathrm{Oi}=$ 前層 $\mathrm{i}$ 番目のニューロンの出力值

$\mathrm{Wji}=$ 前層 $\mathrm{i}$ 番目のニューロンと現層 $\mathrm{j}$ 番目のニュ ーロンとの結合荷重

$\theta \mathrm{j}=し き い$ 值

関数 $\mathrm{f}(\mathrm{X})$ には, シグモイド関数と呼ばれる非線形 な連続関数が一般に使用され，この関数により出力值 は 0 から 1 に制限される（図 2)。

$\mathrm{f}(\mathrm{X})=1 /(1+\exp (-\mathrm{X}))$

出力值は入力デー夕に対応した教師データと比較さ れ，その誤差量が小さくなるように逆方向に伝搬して， 入力層一中間層, 中間層一出力層の結合の強さが修正 される (バックプロパゲーション学習)。この操作を 十分繰り返すことにより，ネットワーク出力值は教師 データに次第に近づいていく。 NN 入力層の各エレメ ントは, 入力変数に対応させた。出力層のエレメント 数は 2 コで, 各々正常（断紙なし）, 異常（断紙発生） に対応し, この出力値の大小で入力变数による状態が 正常, 異常のどちらであるかを判定した。本研究にお ける『学習』とは，『正常時の状態变数が入力された 時には正常エレメントの出力值が大きくなるように, 断紙時の状態变数が入力された時には異常エレメント の出力值が大きくなるように，エレメント間の結合荷 重值やしきい值を修正すること』である。すべての変 数からなる 41 変数モデルを最初にテストした。入力 層 41 , 中間層 10 , 出力層 2 エレメントの NN を構成し, 500 回の繰り返し学習を行つた。学習の進行につれて, 教師信号との出力誤差二乗和, 誤認識回数は減少し, NN は収束した（図 3)。学習終了後の誤認識回数は 4 回/79オブザベーションと, かなり高い精度で断紙の 有無を判別するモデルを得た。ここで $\mathrm{NN}$ がどの変 数を重視してこのような判別を行ったかは興味がある。 そこで荷重逆投影法によって, 入力変数が $\mathrm{NN}$ 出力 にどのように影響を及ぼしているかを調査した。荷重 逆投影とは出力層七ルに対応する荷重行列の值を入力 層まで遡って積和計算したものであり，これによって 学習による結合荷重値の変化を知ることができる。絶 対値の大きい变数が，ネットワーク間の結合荷重が大 きくて，NN が断紙と判定するのに重視している変数 であると考えられる。これら変数を実際の制御や診断 に応用したい時, ある程度入力変数を選択する必要が ある。

そこで次に，より少ない入力変数による NNを作 った。NN 荷重逆投影で影響が強いと考えられた 30

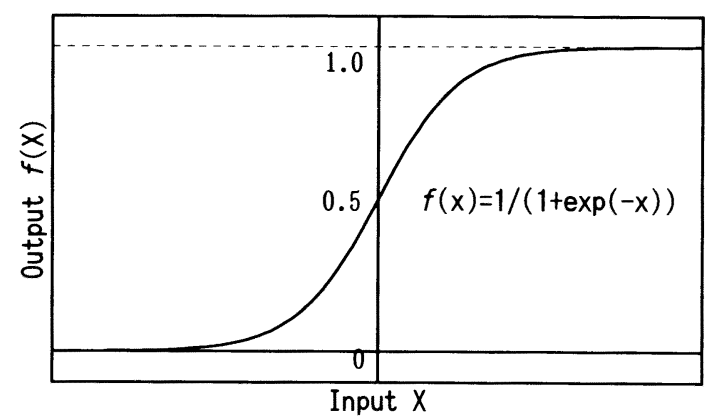

Fig.2 General Sigmoid Function

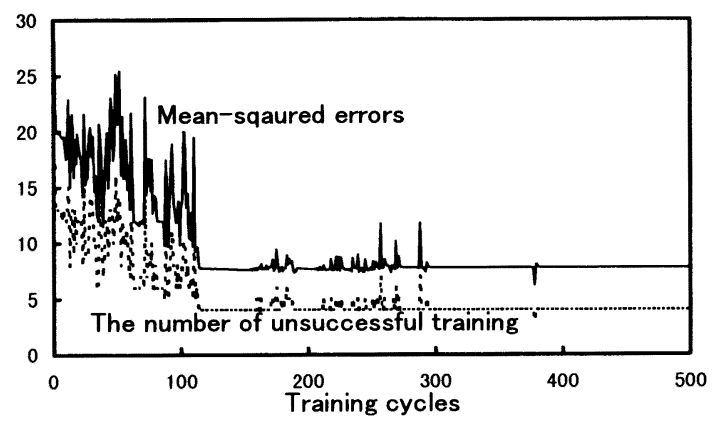

Fig. 3 The back propagation network training cycle

変数により NNの学習を行った。学習の結果, $3 / 79$ と誤認率の低いNNを得ることができた。そこでさ らに重要だと思われる 12 変数による $\mathrm{NN}$ を作った。 中間層エレメント数を 10 ～15 と変化させた 6 種類の $\mathrm{NN}$ を用いた。学習後の誤認率はいずれも $3 / 79$ であ つた。同様にして，この中でもさらに影響の強いと思 われた 5 变数 (白水濃度, インレット温度, 種箱フリ 一ネス, TMP フリーネス, マシンスピード）による $\mathrm{NN}$ を構成した。 5 変数モデルでも，判別の䛊認率は 4/79であり，かなり判別能力の高いモデルを得るこ とができた。下記の $5 つ$ つ結果が, 入力变数や構造の 違う NN を順次検討してきて, 荷重逆投影の傾向が 同じであった結果である（表 2)。操業経験から考え ても妥当であり，いずれも断紙に関して重要なパラメ 一夕と思われた。

*白水濃度が高い (リテンションの低下, 系の污 れ)

*インレット温度が低い（濾水性の低下）

*種箱フリーネスが低い（濾水性の低下）

* TMP フリーネスが高い（シャイブの増加）

*マシンスピードが速い（ドロー，サクションアッ プにより操業環境きびしい) 
Table 2 Important process variables extracted from neural network diagnosis

\begin{tabular}{l|c|l}
\hline \multicolumn{1}{c|}{ Variable } & $\begin{array}{c}\text { Effect on } \\
\text { break }\end{array}$ & \multicolumn{1}{|c}{ Interpretation } \\
\hline White water consistency & ++ & Retention \& Drainage \\
Inlet temperature & -- & Retention \& Drainage \\
Stuff box freeness & -- & Retention \& Drainage \\
TMP freeness & ++ & Shives \\
Machine speed & + & Machine speed \\
\hline Input nodes & 5 & \multicolumn{2}{|c}{ Training cycles 500 } \\
Hidden layer nodes & 8 & \multicolumn{2}{|c}{ Mean squared error 7.5} \\
Output nodes & 2 & \multicolumn{2}{c}{ Unsuccessful training $95 \%$}
\end{tabular}

\section{4. 主成分分析}

多数のプロセス变数データが得られるプロセス解析 においては, 問題の絞り込みや变数の選択が重要であ る。多変量統計解析の目的は, ソースデー夕の持つ本 質的情報をなるべく失うことなく少数の指標にまとめ あげ，現象理解や要因探索を容易にすることである。 デー夕の本質をあまり失わないように，数べクトルの 次元を減らすことを，『次元の縮小』という。主成分 分析とは, いくつかの変数から『主成分 (principal components)』という，互いに無相関な合成変数を つくり次元の縮小を図る多変量解析法である（図4）。 主成分回帰は, 説明变数である主成分が互いに無相関 であるために, 従来の重回帰分析の問題点であった多 重共線性 (説明变数の相関性) や变数選択という問題 がないというメリットがある。主成分分析は, 統計解 析用ソフトSASにより行った。但しこのようなデー タベースに基づく解析で注意することは, 結果はあく まで解析を行ったシステム状態において, 寄与の大き かったものであるということである。すなわち目的変 数に対して重要なパラメータであっても，それがうま
くコントロールされていて変動が小さければ解析結果 には現れてこないことを認識しておく必要がある。得 られた各主成分の固有值, 寄与率は表 3 のようになり, 第 1 5 主成分で全体の変動の約 $60 \%$ が説明された。 上位主成分の固有值, 寄与率, 累積寄与率を示す（表 3)。断紙の有無を目的变数として主成分回帰分析を行 い回帰係数を求めた。第 $1 \sim 3$ 主成分は断紙に対して

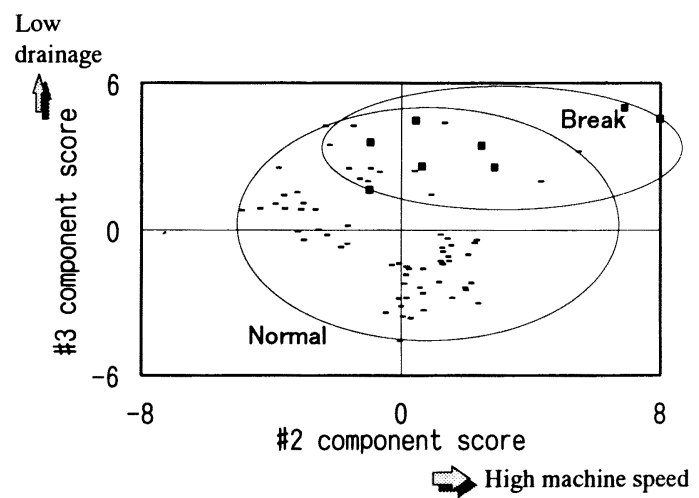

Fig.4 Web break situations presented with the second and the third component

Table 3 Principal component regression analysis

\begin{tabular}{c|c|c|c|c}
\hline \multirow{2}{*}{$\begin{array}{c}\text { Component } \\
\text { number }\end{array}$} & \multicolumn{2}{|c|}{ Principal component analysis } & \multirow{2}{*}{$\begin{array}{c}\text { Regression } \\
\text { coefficient }\end{array}$} \\
\cline { 2 - 4 } & Eigenvalue & Proportion & $\begin{array}{c}\text { Cumulative } \\
\text { proportion }\end{array}$ & \\
\hline 1 & 7.08 & 0.173 & 0.173 & 0.018 \\
2 & 5.75 & 0.140 & 0.313 & 0.038 \\
3 & 5.72 & 0.139 & 0.452 & 0.053 \\
4 & 4.17 & 0.102 & 0.554 & -0.034 \\
5 & 2.26 & 0.055 & 0.609 & no correlation \\
\hline
\end{tabular}


正の影響，第 4 主成分は負の影響があった。第 5 主成 分は断紙にあまり関係なかった。固有べクトルから， 主成分の変動に寄与する主な変数を抽出した。固有べ クトルは元の変数にかかる係数であり, 大きな係数を 持つ変数は主成分の变動に大きく寄与すると考えられ る。第 5 主成分までの固有べクトル成分のうち, 大き な値を持つ変数を表 4 に示す。これらが最終的に抽出 された断紙に大きく影響を与えているパラメータであ つた。表 4 の見方を歩留荗添加率を例にとって説明す る。

固有ベクトル $=-0.349$

主成分回帰係数 $=0.018$

固有ベクトル $\times$ 主成分回帰係数=マイナス

固有ベクトルはマイナスなので歩留剤添加率と第一 主成分には負の相関があり，歩留剤を増加すると第一 主成分は減少する。主成分回帰係数はプラスなので第 一主成分と断紙回数は正の相関があり, 第一主成分が 減少すると断紙が減少する。従って歩留㓮を増やすと
断紙が減少し, 歩留剤の断紙回数への影響はマイナス となることがわかる。同様にして GP フリーネスの断 紙への影響はマイナスなのでフリーネスを高めにして 滤水性が良くなればプレス水分が減少して湿紙強度が 上がり断紙が減少する。インレット温度の断紙への影 響はマイナスなので，インレット温度が上昇して水の 粘度が低下し濾水性が良くなると断紙が減少する。第 二主成分の抄速の影響はプラスである。すなわち抄速 が増加すると断紙が増加する。值が小さいほど真空の 絶対值は大きくなるのでワイヤーサクションボックス とクーチの真空度の断紙に対する影響はマイナスであ る。抄速が上がると真空が強くなり，断紙が増加する ことを示唆している。*印の 3 個の变数は解釈が困難 であった。しかし 41 個の変数の内, 3 個しか異常が なかったと考えると, 実用上は十分な精度であると考 えられる。与えられたデー夕範囲内で, 断紙発生に最 も寄与していた要因は, 主にマシンスピード上昇に伴 う一連の操業変化と濾水度低下に関連するインレット

Table 4 Coefficients in multiple regression and PCA, and their intepretation

\begin{tabular}{|c|c|c|c|c|c|}
\hline No. & $\begin{array}{l}\text { Regression } \\
\text { coefficient }\end{array}$ & Variables & Coefficient & $\begin{array}{c}\text { Effect on } \\
\text { break }\end{array}$ & Interpretation \\
\hline 1 & 0.018 & $\begin{array}{l}\text { Retention aid } \\
\text { Paper stretch } \\
\text { Tensile strength } \\
\text { Tear strength }\end{array}$ & $\begin{array}{r}-0.349 \\
0.283 \\
-0.267 \\
0.257\end{array}$ & $\begin{array}{l}- \\
+ \\
- \\
+(*\end{array}$ & $\begin{array}{c}\text { Retention \& Drainage } \\
\text { Paper strengh } \\
\text { Paper strengh } \\
\text { Paper strengh }\end{array}$ \\
\hline 2 & 0.038 & $\begin{array}{l}\text { Machine speed } \\
2 \mathrm{P} / 3 \mathrm{P} \text { draw } \\
\text { Wire suc. box vacuum } \\
\text { Couch vacuum } \\
\text { DIP ratio }\end{array}$ & $\begin{array}{r}0.335 \\
0.323 \\
-0.323 \\
-0.316 \\
-0.282\end{array}$ & $\begin{array}{l}+ \\
+ \\
- \\
- \\
-(*\end{array}$ & $\begin{array}{l}\text { Machine speed } \\
\text { Machine speed } \\
\text { Machine speed } \\
\text { Machine speed } \\
\text { Paper strengh }\end{array}$ \\
\hline 3 & 0.053 & $\begin{array}{l}\text { Pick up felt vacuum } \\
\text { Paper moisture } \\
\text { GP freeness } \\
\text { Inlet temperature } \\
\text { DIP freeness } \\
\text { Zeta potential }\end{array}$ & $\begin{array}{r}0.347 \\
0.300 \\
-0.298 \\
-0.268 \\
-0.266 \\
-0.250\end{array}$ & $\begin{array}{l}+(* \\
+ \\
- \\
- \\
- \\
-\end{array}$ & $\begin{array}{l}\text { Retention \& Drainage } \\
\text { Paper strengh } \\
\text { Retention \& Drainage } \\
\text { Retention \& Drainage } \\
\text { Retention \& Drainage } \\
\text { Retention \& Drainage }\end{array}$ \\
\hline 4 & -0.034 & $\begin{array}{l}\text { Inlet conductivity } \\
\text { SBKP ratio } \\
\text { SBKP freeness } \\
\text { Basis weight }\end{array}$ & $\begin{array}{l}0.343 \\
0.336 \\
0.335 \\
0.278\end{array}$ & $\begin{array}{l}- \\
- \\
- \\
-\end{array}$ & $\begin{array}{l}\text { Retention \& Drainage } \\
\text { Paper strengh } \\
\text { Retention \& Drainage } \\
\text { Paper strength }\end{array}$ \\
\hline
\end{tabular}

Variables with PCA coefficient whose absolute value is larger than 0.25 is selected.

0.25 is arbitrarily chosen to select 4 to 6 variables in each PC.

(*) Variables whose sign of "effect of break" are difficult to interpret. 


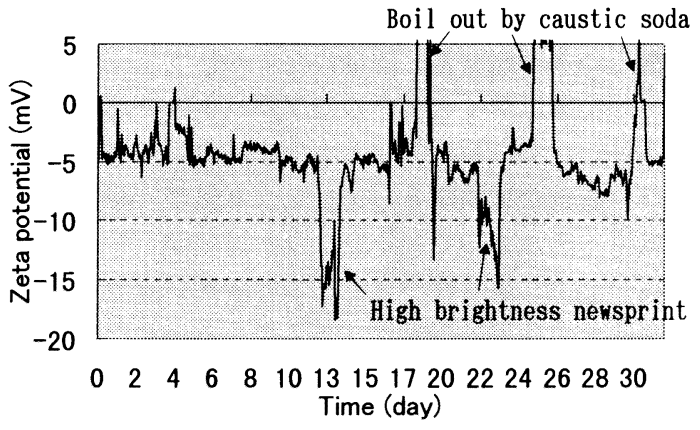

Fig.5 Zeta potential of stock inlet

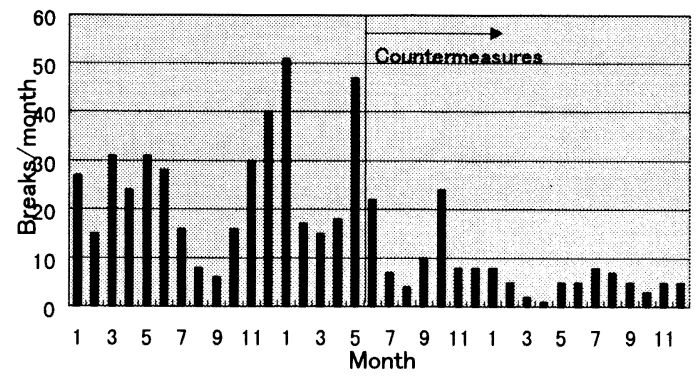

Fig. 6 Web breaks per month

Table 5 Summary of neural network and principal component regression

\begin{tabular}{c|c|c|c}
\hline \multicolumn{2}{c|}{ Interpretation } & $\begin{array}{c}\text { Neural } \\
\text { network }\end{array}$ & $\begin{array}{c}\text { PC } \\
\text { regression }\end{array}$ \\
\hline Common & $\begin{array}{c}\text { Retention \& Drainage } \\
\text { Machine speed }\end{array}$ & -- & -- \\
+ & ++ \\
\hline Uncommon & $\begin{array}{c}\text { Shives } \\
\text { Paper strengh }\end{array}$ & ++ & - \\
\hline
\end{tabular}

温度，フリーネス，ゼー夕電位などの変化であった。 特に寄与率の大きかった第 2 主成分と第 3 主成分のス コア散布図を図 4 に示す。第 2 主成分は主として抄紙 速度を第 3 主成分は歩留まりと滤水度を示している。 断紙発生時のプロットは主に第 1 象限に集中し，正常 操業時とは明確な違いが見られた。すなわち，抄速が 速い時, 歩留まりと濾水度が悪いときに断紙が発生し 易いことが示された。インレットのゼー夕電位は通常 $-5 \mathrm{mV}$ と最適值にあるが，高白色度新聞抄造時には TMP の過酸化水素晒しを強化するので，リグニンや ミセルロースなどが溶解してアニオントラッシュとな り，ゼー夕電位はー $10 \mathrm{mV}$ 以下になる。そのため力 チオン性高分子歩留凨やサイズ剤が効きにくくなり, 断紙し易くなるものと考えられる（図 5)。

\section{5. おわりに}

学習が終了した NNの結合荷重を, 荷重逆投影法 により評価して，断紙に重要な影響を与えていると思 われるパラメータを抽出し，主成分分析の結果と比較 した（表 5)。特に重要だと思われたマシンスピード と紙料温度についての傾向は，主成分分析の結果と一 致していた。また NN からは，白水濃度という主成 分分析からは得られなかった項目もピックアップされ た。これはモデル構造の線形，非線形の違いによるも
のと思われた。この結果はマシン系の安定というのは, 必ずしも線形で言い表されるものではなく，プロセス 変数間のバランスが重要であることを示唆するものと 思われた。抽出された要因については，マシンスピー ドはドローやサクションなどと相関が高く重要な変数 だが, 生産量によって決定される変数なので, アクシ ョンのとりようはない。紙料温度については滤水性の 変動を小さくするという意味で有用である。また白水 濃度に関しては, リテンションエイドによるリテンシ ョンアップが示唆された。解析結果を参考にして工場 ではウエットエンド化学の最適化を行い, 操業面, 設 備面からも様々な対策を実施し, 流質原料と断紙回数 を減少させることができた（図6)。

\section{引用文献}

(1) Venkatasubramanian V., and Chan, K. : "A Neural Network Methodology for Process Fault Diagnosis”, AiChE Journal, 35 (12) 1993 (1989)

(2) Bhat N., and McAvoy T. J. : "Use of Neural Nets for Dynamic Modeling and Control of Chemical Process Systems", Computers Chem. Engng, 14 (4/5) 573 (1990)

(3) Sorsa T., Koivo H. N., and Koivisto H. : "Neural Networks in Process Fault Diag- 
nosis", IEEE TRANSACTIONS ON SYSTEMS, MAN, AND CYBERNETICS, 21 (4) 815 (1991)

(4) Rudd J. B. : "Using a Neural Network System for Advanced Process Control”, Tappi J., 74 (10) 153 (1991)

(5) Sorsa T., Koivo H. N., and Korhonen R. : "Application of Neural Networks in the Detection of Breaks in a Paper Machine", Preprints of IFAC Symposium On-line Fault Detection and Supervision in the Chemical Process Industries, Newark, Delaware, USA, pp. 162-167, April 22-24 (1992)

(6) Dayal B. S., Macgregor J. F., Taylor P.
A., Kildaw R., and Marcikic S. : "Application of Feedforward Neural Networks and Partial Least Squares Regression for Modeling Kappa Number in a Continuous Kamyr Digester", Pulp \& Paper Canada 95 : 11994

(7) Roisum D. R. : "Runnability of paper, Part 1: predicticting runnability” Tappi J., 73 (1) 97 (1990)

(8) Roisum D. R. : "Runnability of paper, Part 2 : troubleshooting web breaks", Tappi J., 73 (2) 101 (1990)

(9) Jolliffe I. T. : "Principal Component Analysis”, 1986 by Springer-Verlag New York Inc. 